NIST Technical Note 1623

\title{
Emergency Egress From Buildings
}

Part 1: History and Current Regulations for Egress System Design

Part 2: New Thinking on Egress From Buildings

Richard W. Bukowski

National Institute of Standards and Technology • U.S. Department of Commerce 
NIST Technical Note 1623

\title{
Emergency Egress From Buildings Part 1: History and Current Regulations for Egress System Design Part 2: New Thinking on Egress From Buildings
}

\author{
Richard W. Bukowski \\ Fire Research Division \\ Building and Fire Research Laboratory
}

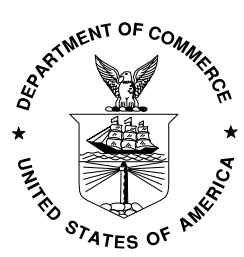

U.S. Department of Commerce Carlos M. Gutierrez, Secretary

National Institute of Standards and Technology Patrick D. Gallagher, Deputy Director 
Certain commercial entities, equipment, or materials may be identified in this document in order to describe an experimental procedure or concept adequately. Such identification is not intended to imply recommendation or endorsement by the National Institute of Standards and Technology, nor is it intended to imply that the entities, materials, or equipment are necessarily the best available for the purpose.

National Institute of Standards and Technology Technical Note 1623

Natl. Inst. Stand. Technol. Tech. Note 1623, 28 pages (January 2009) CODEN: NSPUE2 


\title{
Emergency Egress from Buildings Part 1: History and Current Regulations for Egress Systems Design
}

\author{
Richard W. Bukowski, P.E., FSFPE \\ NIST Building and Fire Research Laboratory \\ Gaithersburg, Maryland 20899 USA
}

\section{INTRODUCTION}

For most of history buildings were short enough that stairs provided for access were sufficient for rapid egress in the event of fire. Even in single stair (mostly residential) buildings, experience showed that this stair was sufficient for fire egress as long as the fire did not expose or block access to the stair. Fire resistant apartment doors shielded the stair from most fires and exterior fire escapes provided a second egress path beginning early in the $20^{\text {th }}$ Century.

The 1854 invention of the elevator safety brake enabling the passenger elevator is credited with facilitating increases in building height and the first so-called skyscraper in Chicago in 1885. These buildings utilized steel frames protected by masonry or tile and were dubbed "fireproof construction" providing a (possibly false) sense of security. By 1914 authorities had begun to question these arrangements as evidenced by a move to change the term "fireproof" to "fire-resistive," and description of egress provisions in regulations as "exceedingly deficient."1

Model building regulations in the US started with the National Building Code published by the National Board of Fire Underwriters (NBFU) following the Great Fire of Boston (1872). Property loss claims from this fire resulted in more than 70 insurance companies being driven into bankruptcy, causing insurance interests to form the NBFU and to develop building fire safety rules aimed at reducing property losses in fires. These rules became the first model building code, called the National Building Code (NBC), and first published in 1905. The NBFU was able to tie compliance with their rules to their Municipal Grading Schedule on which insurance rates are based. Cities needed favorable rates to attract investment, so they were motivated to adopt regulations consistent with the National Building Code ${ }^{2}$. The first (1905) edition of the NBC required exit stairs to have a minimum width of 20 in $(510 \mathrm{~mm})^{*}$.

The purpose of this paper is to document current regulatory requirements for means of egress in fires, their origins and scientific basis, and the approaches used in other countries. Then the paper will present an argument for why these approaches and requirements should be re-evaluated to reflect changes both in buildings and in their occupants. Finally the paper will make some suggestions for reasonable revisions to

\footnotetext{
* This paper will cite primary dimensions in the units found in the code cited. Thus U.S. codes will show English units first and non-U.S. will show metric first. Unit conversions are approximate because the paper cites the equivalent values found in the building regulations of various countries which are normally round numbers.
} 
design practice along with a more holistic philosophy that takes better account of human behavior and is based on a more appropriate performance metric.

\section{ORIGINS OF THE 44 INCH EXIT STAIR IN THE US}

In the 1913 National Fire Protection Association (NFPA) Proceedings ${ }^{3}$, the Committee on Fireproof (later, Fire-Resistive) Construction reported a number of recommendations, including one for minimum 44-in exit stairs (unobstructed width except that handrails would be permitted to intrude not more than $3 \frac{1}{2} 2$ in on each side). That same year NFPA formed their Committee on Safety to Life. That committee's first activity was to conduct a comprehensive review of fire safety issues and regulatory approaches found in building codes and local regulations in several, geographically diverse cities. At the NFPA's 1914 meeting they reported that,

“... existing laws are exceedingly deficient in this very important matter of egress. A number of states report frankly that they have no real legislation upon the subject, many City Ordinances are of the most indefinite character, and in some the matter is simply left to the discretion of the fire department or other officials."

In the 1914 NFPA Proceedings, section on egress, the Safety to Life Committee cites the 1913 NFPA Annual Meeting report of the Committee on Fire-Resistive Construction in which they said was presented,

“... a splendid set of specifications for the construction of a standard building. Egress received detailed attention; -- specifications for smoke-proof towers, for stairs, for horizontal exits, and for the capacity of vertical and horizontal exits were included."

The committee also cites the 1913 laws of the New York State Department of Labor which, “... as regards fundamentals appear to agree entirely with the requirements of our Committee ..." Extracting from the referenced New York statute, they cite, " $a$. For buildings erected in the future, a minimum of 22 inches of stair width shall be required for not to exceed 14 persons on any one floor.

$b$. On buildings already erected this figure is reduced to 18 inches as a minimum.

c. A 44-inch stair in new buildings permits 28 persons to be housed on each floor above the first one.

d. In arriving at this decision the idea has been that all of the persons on all floors shall be able to remain in the stair tower without any movement, a person requiring about 22 inches in width, and one person to stand on every other stair."

They further characterize the New York laws' stair geometry (7 3/4 in riser height by 10 in tread) as "good", and that they recommend a minimum 44 inch wide stair for new buildings as this width is

"reported sufficient to prevent three persons from forming an arch and blocking traffic."

\section{EXIT CAPACITY}

The above explains why the US designs exits for "capacity" and why the capacity is based on the population of a single floor. The exit is sized to "store" people, motionless 
within the protected exit enclosure, such that the population of one floor will fit within one flight of the stair, with each person in a space 22 inches wide and standing on every other step.

This philosophy was recognized in the 1935 National Bureau of Standards (NBS now NIST) publication, Design and Construction of Building Exits ${ }^{4}$. Developed by the Department of Commerce Building Code Committee, this report included survey data on exit sizes and configurations drawn from eight cities chosen, “... with a view to covering places varying in size and sufficiently distributed to give a fair cross section of building construction." The survey included population counts on typical floors and compiled data on movement of people in buildings (railway terminals and schools). Studies of the flow of occupants of government buildings during fire drills were conducted and the data presented as discharge rates for stairs (as a function of width and stair geometry), ramps, and doorways.

The data were used to suggest possible approaches to calculating minimum width of exits necessary to provide for occupant safety. These included (note that the descriptive text is paraphrased from the 1935 report):

1. Capacity Method, which is based on the concept of storing occupants on the stairs within a protected stair enclosure, and allowing for the subsequent safe and orderly evacuation of the building. It recognized that travel down a long series of stairs in high buildings is exhausting even to normal persons. Objections of building owners over the loss of rentable space are noted as well as the comment by some authorities that people may not stand still in stairways, even in high buildings.

2. Flow Method, which is based on the concept that people will move down the stairs at a typical flow, assumed to be 45 persons per 22 in unit of width per minute and 60 persons per minute through doorways. It is stated that this method is usually coupled with an assumed time in which it is safe to exit the building and that this method calls for considerably less stairway width than the capacity method. However they felt that it would be limited to a few occupancies and to buildings of low to moderate height since continuous movement down stairways in high buildings cannot be expected without serious effects on some occupants.

3. Combined Method suggests the flow method for lower buildings shifting to the capacity method for taller buildings also accounting for type of construction and use. Once again they point out that tall buildings would require a disproportionate amount of space devoted to stairways as compared with useable floor area.

4. Probability Method considers only the population of the six, most densely populated floors since it is improbable that simultaneous evacuation of all floors of a large building is needed. This is the first time that phased evacuation (as currently practiced in tall buildings) is suggested.

5. Floor Area Method relates area to units of exit width needed as a function of construction type and use. Like the probability method, simultaneous evacuation of all floors is not considered but the number of floors considered varies with occupancy. 
In the end, the 1935 report suggests that the needs of the vast majority of buildings can be met with the provision of two, two-unit-width (44 in) stairs. The capacity method (occupants waiting within the exit enclosure) is appropriate for low buildings with a gradual shift to the flow method for taller buildings where people will be less comfortable waiting in the stair. For tall buildings the floor area method has some application as these are of fire resistive construction and only those near the floor of origin are initially at risk but six floors is not sufficient for larger buildings. They suggest half of the floors should be considered.

\section{EARLY THOUGHTS ON ELEVATORS AS A MEANS OF EGRESS}

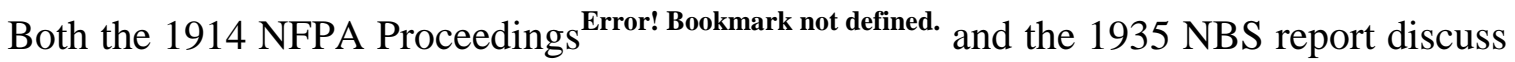
the possible use of elevators for egress from tall buildings. In 1914 the Committee on Safety to Life expressed the opinion that, “... elevator shafts properly enclosed and with openings adequately protected have decided value from an escape standpoint, and are absolutely necessary in high buildings." They cited as “... loss of life possibilities in many modern so-called fireproof buildings ..." the common practice of unenclosed stair and elevator shafts that might permit a fire in lower stories that, “... spread with unexpected speed could result in a loss of life which would stagger the civilized world." The Committee called for enclosing elevator shafts, improving the fire resisting powers of elevator doors, ensuring the integrity of the electric current applied to elevators, and "drilling" elevator operators in emergency procedures, including that persons in the upper stories shall first be taken to the ground.

The 1935 NBS report discusses a credit for elevators against required aggregate exit width. They discount automatic elevators as unsuitable as their "...capacity and rate of speed is not great." And "... they are not subject to a single will as in the case of an elevator operator, but to demands from many tenants." While there was a suggestion in the formulae of the flow method that five elevators might be equal to a single unit of exit stair width for some construction types and use, in the end they concluded that the uncertainties were such that no direct credit be given for elevators but to recognize their availability in high buildings.

\section{EARLY REGULATORY APPROACHES IN THE US}

The 1914 report of the Committee on Safety to Life included detailed recommendations for the design and arrangement of egress stairs and fire escapes with the intent that this material would be incorporated by others into building regulations. No code or standard was produced by the Committee until the 1927 publication of the first edition of the NFPA Building Exits Code (NFPA 101-T) ${ }^{5}$ which later became the Life Safety Code.

The 1927 edition of NFPA 101-T defined stairs as Class A, B, or C. Class A stairs were the main stair of a newly-constructed Assembly occupancy, and were 44 in (1100 mm) wide (handrails could intrude not more than $31 / 2$ in $(89 \mathrm{~mm})$ on each side) with a rise of not more than 7 in $(178 \mathrm{~mm})$ and a tread of not less than $101 / 2$ in $(267 \mathrm{~mm})$. Class B stairs were for new construction of all stairs not required to be Class A, and for existing 
construction where Class A stairs would be required if new. Class B stairs were the same width as Class A but the rise was permitted to be not more than $73 / 4$ in $(197 \mathrm{~mm})$ with a tread of not less than $91 / 2$ in $(241 \mathrm{~mm})$. Class $C$ stairs covered existing stairs in existing buildings and were at least 36 in $(0.9 \mathrm{~m})$ wide (not less than $32 \mathrm{in}, 0.81 \mathrm{~m}$ between handrails, but stairs less than 44 in $(1100 \mathrm{~mm})$ wide only required a handrail on one side). Occupant load on a floor dictates required capacity (total width of stairs in number of 22 in units) required in a minimum of two stairs located "as remote as practical."

The 1935 NBS report included recommended code language in an appendix that did not follow any of the five methods for calculating minimum exit widths discussed previously. They explained that tentative requirements were drawn up and compared against the results of the field studies. Eventually a consensus of the Committee was reached and was presented in the recommended code language.

The suggested code requirements largely followed the capacity method for at least two stairs of two (22 in, $550 \mathrm{~mm}$ ) units of exit width each, with the floor area method used (by means of occupancy load factors consistent with those found in current regulations) to determine aggregate width. No suggestions of maximum egress time (including no references to fire resistance times associated with construction types, building height, and use) that might facilitate the use of the flow method, and no mention of partial evacuation of tall buildings as discussed in the probability and floor area methods was made. These recommendations were consistent with those in the 1927 edition of NFPA 101-T, but this is not surprising since the Committee on Safety to Life was represented on the NBS Committee. The requirements suggested in the NBS report and NFPA 101 were adopted in the model codes and building regulations throughout the US until the mid-1980's when the 22 in (550 mm) unit of exit width was abandoned for assessing exit capacity in units of people per inch, but retaining the 44 in $(1100 \mathrm{~mm})$ minimum width. This method provides similar results for aggregate exit width but provides more capacity credit for fractions of the 22 in unit.

\section{SCIENTIFIC STUDIES OF FLOW RATE}

The 1935 NBS report included field surveys of discharge rates down exit stairs and through doors for various government buildings during drills and for subway and rail terminals at rush hours. The data collected were discussed by the Committee and a consensus reached that there was a clear correlation between width and flow. The committee agreed that, “... rates of 45 persons per 22-inch unit per minute for travel down stairways, and 60 persons per 22-inch unit per minute through doorways, which had been in use on the basis of earlier observations, were sufficiently confirmed to warrant their retention in connection with the requirements under development."

Almost from the start there were issues raised with the assumed flow rate on stairs of 45 persons per minute per (22 in) unit of exit width. Togawa ${ }^{6}$ in Japan conducted research in the 1940's and 50's, that showed for densities above 1 person per square meter (10 square feet) that flow rates decreased significantly. His data suggested a flow rate of 26 persons per minute per (22 in) unit of exit width. 
Pauls has published extensively on this topic and continues to be the scientific conscience of stair design in the US codes. Pauls ${ }^{7}$ and Fruin ${ }^{8}$ both discussed the concept of effective width of a stair, which is generally $0.3 \mathrm{~m}(1 \mathrm{ft})$ narrower than the actual width due to the natural tendency of people to keep a distance from walls and handrails. Fruin further spoke of the personal space (buffer) around people that increases their effective space requirement. Pauls found that for people walking on stairs their body sways from side to side and they desire sufficient space so that they do not make contact with the person beside them. Pauls work confirmed that of Togawa finding that flow rate in stairs at typical densities is about 27 persons per minute per (22 in) unit of exit width. Extensive studies in Russia also confirmed the effects of density on flow rates including the values suggested by Pauls and Togawa, as reported in a 1969 book by Predtechenskii and Milinskii ${ }^{9}$.

From the data collected by NIST in the investigation of the World Trade Center (WTC) collapse on September 11, 2001, the flow rate in the stairways can be estimated ${ }^{10}$. For WTC 1, there were approximately 7900 survivors who exited the building over the 102 minutes between the aircraft strike and the collapse. The building had three stairs, two at 44 in $(1100 \mathrm{~mm})$ and one at 56 in $(1400 \mathrm{~mm})$. Assuming the occupants used the stairs equally, there were 2630 people in each 2-unit wide stair who exited in 102 minutes, or 13 people per minute per unit of exit width. The NIST study found that the egress flow decreased by about $80 \%$ in the last 20 minutes before collapse. If one assumes the 2630 people exited in 82 minutes, the flow rate would be 16 people per minute per unit of exit width. These estimates support the argument that current flow rates may be significantly less than the rate suggested by Pauls and Togawa in the 1970's and one third the rate proposed in $1914^{\text {Error! Bookmark not defined. }}$

\section{SCIENTIFIC STUDIES OF EXIT WIDTH}

Clearly, the current 44 in (1100 mm) minimum exit stair width is intended to support two, 22 in queues of occupants either standing still (capacity method) or moving down the stair (or a single queue of occupants moving down and being passed by firefighters moving up, known as counterflow). The 22 in dimension for the width of a person was offered in 1914 as originating with soldiers standing in a line ${ }^{\text {Error! Bookmark not defined. }}$.

Challenges to the adequacy of the 22 in dimension include the need to provide for body sway as people move down the stair (Pauls), and the need to allow for some personal space (Fruin, Predtechenskii and Milinskii). Recently, the adequacy of the basic 22 inch dimension is being questioned in light of the increasing size and weight of the typical person, especially in the US. The 22 inch dimension refers to the width of a person at the shoulders, which is assumed to be the widest part. Predtechenskii and Milinskii suggest that 4 in $(100 \mathrm{~mm})$ be added to each side to allow for a personal buffer except that for low obstructions (like handrails) the additional space is not needed since one's shoulders are at a higher level and will extend over the obstruction. 
From anthropometric data for modern Americans, the width at the hip is approaching the width at the shoulder, and it seems that this exception may no longer be valid. Thus, with the shoulder width of the $97.5^{\text {th }}$ percentile adult male reaching 20 in $(510 \mathrm{~mm})^{11}$ and allowing the 4 in on each side for handrail and personal space, the new unit of exit width should be 28 in $(700 \mathrm{~mm})$ and the minimum stair width 56 in $(1400 \mathrm{~mm})$, see Fig 1.

Arguably the most comprehensive studies of movement on stairs were

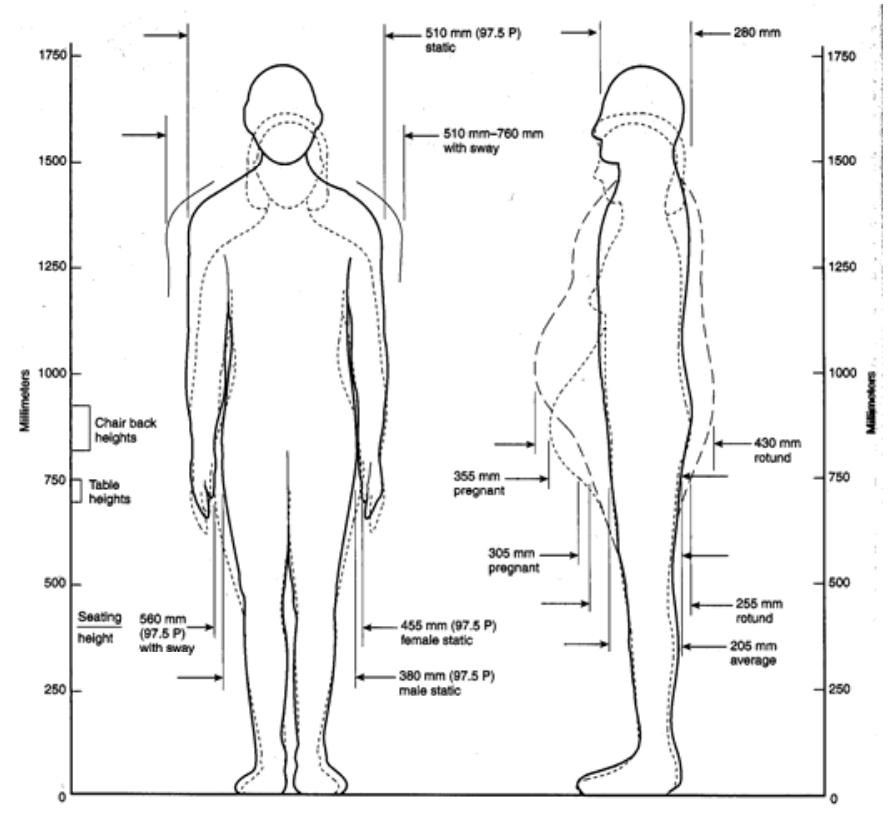
conducted by Templer, beginning with his doctoral research ${ }^{12}$ and including work at $\mathrm{NBS}^{13}$ in the 1980's. Templer observed the movement of many

Figure 1 Anthropometric data for adults Reprinted with permission from NFPA $101 \circledR$ the Life Safety Code ${ }^{\circledR}$, copyright $\odot 2006$ National Fire Protection Association individuals up and down stairs of varying width and tread geometry, tabulating variables ranging from quantitative (speed, number of stumbles) to qualitative (perceived comfort). From this work Templer concluded that the minimum width of an egress stair should be 56 in $(1400 \mathrm{~mm})$.

\section{SCIENTIFIC STUDIES OF TREAD GEOMETRY}

One of the earliest studies of stair geometry was conducted by an architect in France named Francois Blondel ${ }^{14}$. Blondel was primarily interested in comfort rather than safety and observed that the main stairs of classic cathedrals were comfortable to use and accommodated large numbers of people attending services. He made measurements and found that the ratio of stair height to tread depth was a constant, and he related this dimension to the length of the human gait. His formula was $2 R+G=24$ in, where $R$ is the rise and $\mathrm{G}$ is the going (or run). Templer adjusted Blondel's formula for the use of the old (pre French Revolution) inch and a modern gait more like 28 in $(71 \mathrm{~cm})$ and arrived at a modern (metric) formula, $2 \mathrm{R}+\mathrm{G}=710$. The so-called $7 / 11$ stair geometry commonly required in US codes meets the relation $2 \mathrm{R}+\mathrm{G}=635$.

Templer ${ }^{15}$ summarizes a number of research studies of stair geometry and safety. Many such studies were conducted by observing people moving up or down stairs in buildings. Observations in subway or train stations at rush hours provided data for higher population densities. A few studies were conducted in laboratory settings on specially constructed stair sections where the geometries and stair angle could be varied systematically. Templer himself conducted several of these studies, including some at NBS. 
Most of the studies reviewed concluded that the measure of Total Energy Cost per Meter Rise is a useful metric for the evaluation of stair design for normal use and comfort; however stair safety is more closely related to the likelihood of missteps which is a function of how the stair relates to the human gait. In both cases the effect is different for ascent and descent, with descent being more hazardous.

When ascending a stair a person walks on the ball of the foot with less of the foot placed on the step. Shorter treads (goings) and higher risers produce fewer missteps. When descending a stair the heel and most of the foot needs to be placed on the tread. Too much of the front of the foot extending over the nosing results in rotation of the foot and a fall, or a distorted gait while trying to place more foot on the tread. Tread depths of at least 11 in $(280 \mathrm{~mm})$ are recommended to accommodate the $95^{\text {th }}$ percentile foot, but considering only gait and accident history treads (goings) of at least 9 in $(230 \mathrm{~mm})$ are required. Riser heights of 6.3 in to $7.2 \mathrm{in}(160 \mathrm{~mm}$ to $183 \mathrm{~mm})$ had the fewest missteps. Other dimensions apply to curved stairs ${ }^{16}$.

Other factors relevant to stair safety include lighting, slip resistance, single steps (most codes prohibit flights of fewer than three steps), handrails, and inability to detect the edge of the tread due to lack of contrast.

\section{REVIEW OF INTERNATIONAL CODE REQUIREMENTS FOR EGRESS STAIRS}

The building regulations summarized below are from countries that are widely disbursed and culturally different, and should be representative of any range of methods used to treat egress. Where the original code documents are published in languages other than English, the codes used were official translations published in English, so they can be presumed accurate.

Characteristics of egress stair design include the factors previously discussed as well as the minimum number of egress stairs provided, maximum travel distance to a stair, width of doors and passageways, interior finish, lighting and marking, headroom, and handrails. All of the codes examined address all of these characteristics and all are reasonably consistent in requirements. For example, all require handrails on both sides of an egress stair and a center handrail when stair width exceeds $1800 \mathrm{~mm}$ (71 in). It is interesting to note that, while all the codes require a minimum of two egress stairs from every floor, many of the codes address specific conditions in which a single stairway is permitted, and some are quite liberal in this regard. Design occupant loads are generally consistent among most building regulations in the world.

\section{United States}

In the United States model building regulations are developed by private sector, nonprofit organizations and are adopted by State and local governments with modifications that reflect local needs and practices. Two such model codes exist but the requirements of both are reasonably consistent, especially with respect to egress system design. A 
detailed review of current US building code requirements for egress system design is provided by Bukowski and Kuligowski ${ }^{17}$.

In the US codes, the minimum width for an egress stair is $1100 \mathrm{~mm}$ (44 in) except that a space served by no more than 50 people can have a $900 \mathrm{~mm}$ (36 in) stair. The capacity of a stair (number of people served per floor) is 0.3 in per person unsprinklered and 0.2 in per person sprinklered. Thus, for the $1100 \mathrm{~mm}$ (44 in) stair the capacity is 147 unsprinklered and 220 sprinklered. As an example, the design occupant load for offices specified in US building regulations is $10 \mathrm{~m}^{2}$ per person (100 $\mathrm{ft}^{2}$ per person).

\section{Australia}

In Australia the legal responsibility for regulation of buildings rests with the States and Territories. Since 1996 a national model building code, the Building Code of Australia (BCA) has been developed under a mutual agreement (and funding) by the Australian Building Codes Board, and is adopted with local modifications by the States and Territories. The local modifications are published as individual annexes in the BCA document.

The BCA $2006^{18}$ is a performance-based code that includes prescriptive requirements drawn from the predecessor code as deemed-to-satisfy requirements within the published code document. While it is common to use performance analysis to address such issues as travel distances, remoteness requirements, or fire resistance requirements for shaft enclosures, stair geometries and minimum widths generally comply with the prescriptive rules.

The minimum clear width (between handrails) of a required exit stair serving a storey or mezzanine accommodating up to 100 people is $1000 \mathrm{~mm}$ (39 in). Stairs serving a storey that accommodates more than 100 but not more than 200 must have an aggregate width of at least $1000 \mathrm{~mm}$ (39 in) plus $250 \mathrm{~mm}$ (10 in) for each 25 people (or fraction thereof) in excess of 100, and stories accommodating more than 200 must have an aggregate width of $2000 \mathrm{~mm}$ (78 in) plus $500 \mathrm{~mm}$ (20 in) for every 75 people (or fraction thereof) in excess of 200 unless the stair or ramp is steeper than 1 in 12, when the additional 500 $\mathrm{mm}$ (20 in) is for every 60 people in excess of 200. Design occupant loads are similar to the US codes. For example, for offices the design load is $10 \mathrm{~m}^{2}$ per person which is identical to the US $100 \mathrm{ft}^{2}$ per person.

Stair geometry is specified as a range for both the riser (rise) and going (tread), along with a range of the ratio of twice the riser plus the going (Blondel's formula). The values specified are a riser between $115 \mathrm{~mm}$ and $190 \mathrm{~mm}$ (4.5 in and $7.5 \mathrm{in}$ ), a going between $250 \mathrm{~mm}$ and $355 \mathrm{~mm}$ (10 in and $14 \mathrm{in})$ and the ratio (2R+G) between 510 and 700 .

\section{United Kingdom}

The UK building regulations apply to England and Wales but not in Scotland or Ireland. In 1985 UK adopted a performance-based code and converted its prescriptive rules to 
Approved Documents which represent deemed-to-satisfy rules. Approved Document $\mathrm{B}^{19}$ deals with Fire Safety.

Section 5 deals with Design for Vertical Escape for buildings other than Dwellings, with minimum stair widths for simultaneous evacuation on Table 7 and for phased evacuation in Table 8. Table 7 lists the maximum capacity (number of persons served) as a function of stair width and number of floors. Stair widths range from $1000 \mathrm{~mm}$ (39 in) to 1800 $\mathrm{mm}$ (71 in) with the provision that stairs wider than $1800 \mathrm{~mm}$ must be divided by a handrail. Thus the minimum permitted width is $1000 \mathrm{~mm}$ (39 in). For a stair of 1100 mm equivalent to the US minimum 44 in stair, 260 people can be accommodated on two floors, increasing by 40 people for each additional floor. For phased evacuation 120 people per floor can be accommodated by a $1100 \mathrm{~mm}$ (44 in) stair with an additional 10 people for each $100 \mathrm{~mm}$ (4 in) in width. Design occupant loads in Approved Document $\mathrm{B}$ are somewhat more conservative than in other codes, for example offices are $6 \mathrm{~m}^{2}$ (60 $\mathrm{ft}^{2}$ ) per person.

Some insights into the development of the table appear in the supporting text in Approved Document B. Provision 4.25 presents an alternative to using Table 7 for stairs $1100 \mathrm{~mm}$ (44 in) or wider to determine number of persons served (P) for simultaneous evacuation by applying the formula $\mathrm{P}=200 \mathrm{w}+50(\mathrm{w}-0.3)(\mathrm{n}-1)$. Note 5 to this formula explains that 200w represents the number of persons estimated to have left the stair after 2.5 min of evacuation and the second term represents the number accommodated on the stair at that time. This implies that they are assuming a flow of 45 persons per minute per $510 \mathrm{~mm}$ (22 in) of width and a storage capacity of 50 people per (meter minus 0.3 , which may represent Fruin's boundary space) in each story of stairway. This appears to follow the 1935 NBS recommendation for a combination of the flow method and the capacity method with the assumption that the first $2.5 \mathrm{~min}$ of evacuation time is safe.

It is also interesting to note that Approved Document B suggests that buildings in excess of $30 \mathrm{~m}(100 \mathrm{ft})$ in height be designed for phased evacuation. This has somewhat different stair capacity requirements but also suggests that the capacity should be provided by the stairs remaining after any one is discounted as being used by the fire service for fire attack. Appropriate arrangements are to be worked out for specific building conditions in consultation with the fire brigade. This is in addition to a requirement that buildings in excess of $30 \mathrm{~m}$ (100 ft) in height be equipped with a firefighting shaft including a protected elevator dedicated to emergency response service.

\section{Spain}

Spain has a national building regulation developed by the Ministry of Housing and issued by Royal Decree. Like Australia, Spain recently adopted a performance-based building regulation that includes deemed-to-satisfy requirements within the code that are based on the traditional rules. Because Spain is a Member State of the European Union (EU) they fall under the Construction Products Directive of the EU which requires coordination of construction regulations so that the regulations do not become a barrier to free trade within the Union. 
The Spanish regulations ${ }^{20}$ (Section SI 3, table 4.2) assign evacuation capacity (number of occupants who may use the stair) of protected stairs as a function of stair width and number of floors to be traveled. For unprotected stairs they assign different values for travel upward and downward as a function of width. Stair widths ranging from $1000 \mathrm{~mm}$ (39 in) to $2400 \mathrm{~mm}$ (95 in) are covered, implying a minimum width of $1 \mathrm{~m}$ (39 in). A $1100 \mathrm{~mm}$ (44 in) wide stair corresponding to the US minimum, can accommodate 248 people on two floors, increasing by 36 people for each additional floor.

Occupant loads in the Spanish code are consistent with other countries; e.g., offices are $10 \mathrm{~m}^{2}\left(100 \mathrm{ft}^{2}\right)$ per person. Stair geometry is regulated in the code section on protection from falling (Section SU) where stair treads must be at least $280 \mathrm{~mm}$ (11 in) and risers $130 \mathrm{~mm}$ (5 in) and no more than $185 \mathrm{~mm}$ (7 in), with the tread to riser ratio of 4:1 for the entire length of the stair.

\section{Hong Kong}

The Hong Kong building regulations are prescriptive and derive from the British rules. Following the return of Hong Kong to Chinese sovereignty their designation as a Special Administrative Region (SAR) permitted them to continue using prior regulations. There is a separate document for Means of Escape in Case of Fire ${ }^{21}$ (MOE). Table 5 (unsprinklered building) and Table 6 (sprinklered building) are similar to the Spanish table, providing a discharge value (number of occupants who may use the stair) as a function of width and number of stories. Widths range from $1050 \mathrm{~mm}$ (41 in) to 1900 $\mathrm{mm}$ (75 in) in $150 \mathrm{~mm}$ (6 in) increments, and values for widths exceeding $1900 \mathrm{~mm}$ are permitted by linear extrapolation (without limit). A $1100 \mathrm{~mm}$ (44 in) wide stair corresponding to the US minimum, can accommodate 242 (unsprinklered) or 452 (sprinklered) people on two floors, increasing by 32 people for each additional floor.

Occupant loads in the Hong Kong code are only slightly greater than other countries; e.g., offices are $9 \mathrm{~m}^{2}\left(90 \mathrm{ft}^{2}\right)$ per person. Stair geometry requirements specify treads at least $225 \mathrm{~mm}$ (9 in) and risers not more than $175 \mathrm{~mm}$ (7 in).

The Hong Kong MOE includes a unique requirement for refuge floors in buildings exceeding 25 stories in height. Every 25 stories an unoccupied floor (normally a mechanical floor) must arrange at least $50 \%$ of its area as an area of refuge (2 h fire separation) for occupants to rest or to cross between stairways. They are required to be open on at least two sides (with water curtains) above a safe railing height to provide natural smoke control. They must be served by a fireman's lift to facilitate rescue assistance. These requirements have also been adopted in other areas of China and in some other Asian countries.

\section{Peoples Republic of China}

Regulations for building fire safety in China are contained in the Code for Design of Building Fire Protection ${ }^{22}$ (GBJ 16-87) and published as a National Standard that is locally enforced. Section 5.3 deals with Safety Evacuation of Civil Buildings. 
The total width of stairs is specified per 100 people for buildings of specific height (in stories) and construction class (1 through 4) along with a minimum width of any stair of $1100 \mathrm{~mm}(44 \mathrm{in})$. While the definitions of the Chinese construction classes do not align completely with those specified in US codes, an approximate correlation is presented below.

Class 1 or 2 buildings (similar to US Type IA and IIIA) require a minimum aggregate width of $650 \mathrm{~mm}$ (26 in) per 100 people for 1 and 2 story buildings, $750 \mathrm{~mm}$ (30 in) per 100 people for 3 story and $1000 \mathrm{~mm}$ (39 in) per 100 people for 4 story or higher. Class 3 buildings (similar to US Type IIIB) require a minimum aggregate width of $750 \mathrm{~mm}$ (30 in) per 100 people for 1 or 2 story, $1000 \mathrm{~mm}$ (39 in) for 2 story and $1250 \mathrm{~mm}$ (49 in) for 4 story or higher. Class 4 buildings (similar to US Type IV heavy timber) require 1000 mm (39 in) per 100 people for 1 and 2 story buildings. Class 4 buildings are not permitted taller than 2 stories.

\section{Japan}

Japan regulates building safety through a national law that is promulgated by the national government, through the Ministry of Land, Infrastructure, and Transport (MLIT). The Building Standard Law of Japan ${ }^{23}$ (BSL) is utilized nationally without local amendment and is enforced by local officials who are empowered to determine compliance or lack thereof, but not empowered to issue variances or determination of equivalencies. These can only be determined by the MLIT. Unlike most building regulations the BSL combines building and zoning regulations.

Beginning in 2000 the Building Standard Law was revised to a performance-based structure with the prescriptive rules moved into the Building Standard Law Enforcement Order to facilitate updating and interpretation.

Chapter II, Article 23 deals with stairs which may be through stairs or escape stairs. This article establishes a minimum stair width of $1200 \mathrm{~mm}$ (47 in) with stair treads of $240 \mathrm{~mm}$ (9.5 in) or more and a rise of $200 \mathrm{~mm}$ (8 in) or less.

Chapter V of the BSL Enforcement Order deals with Evacuation Facilities. Article 120 addresses through stairs provided for access and egress, and article 121 requires that at least two through stairs be provided. Article 122 requires that certain through stairs be designated as escape stairs and be constructed in accordance with article 123. None of these articles address stair width or geometry. Article 124 requires that the aggregate width of escape stairs in stores (mercantile) be not less than $600 \mathrm{~mm}$ (24 in) per $100 \mathrm{~m}^{2}$ $\left(1000 \mathrm{ft}^{2}\right)$ of floor area of the largest floor served by the stair.

It does not appear that the Japanese code incorporates the concept of occupant load but rather specifies required stair capacity in terms of the floor area served, which is the equivalent of applying a uniform occupant load to all use categories in the group. The Japanese code typically groups assembly type uses, educational, mercantile, and residential uses when specifying minimum widths of stairs, doors, and corridors. 


\section{Part 2: New Thinking on Egress from Buildings}

\section{BUILDINGS ARE TALLER}

At the start of the $20^{\text {th }}$ Century the tallest building in the world (Park Row Building in Manhattan) stood just 391 feet $(119 \mathrm{~m})$. By 1913 the record height had doubled with the completion of the Woolworth Building at 792 feet (241 m). Record heights crossed the thousand foot mark in 1930 with the Chrysler Building (1046 feet, 319 m)) and went to 1250 feet $(381 \mathrm{~m})$ with completion of the Empire State Building the following year (1931). The World Trade Center (1368 ft, 417 $\mathrm{m}$ in 1971), Sears Tower (1450 ft, 442 $\mathrm{m}$ in 1974) and Petronas Towers (1486 $\mathrm{ft}, 448 \mathrm{~m}$ in 1998) ended the century with the tallest building record just short of 1500 feet $(457 \mathrm{~m})$.

The early $21^{\text {st }}$ Century has seen a rapid surge skyward, first in Asia and then in the Middle East. The height record (as of this writing) is Taipei 101 at $1671 \mathrm{ft}$ (510 m), but several taller buildings are under construction. The Burj Dubai Tower is estimated to top out at no less than $2624 \mathrm{ft}(800 \mathrm{~m})$ and there is said to be a building planned for elsewhere in the Middle East at $3280 \mathrm{ft}(1000 \mathrm{~m})$.

Prior to the World Trade Center Towers, nearly all the tall buildings were tapered (or stepped) for a number of reasons, ranging from reducing structural loads to not casting shadows on neighboring buildings (see Fig 2). This meant Source: Skyscraper Museum (used with permission) that the occupant load decreased on the higher floors, decreasing the cumulative load on the stairs, unless there was an assembly use at the top such as an observation deck or restaurant. Today, most of the taller buildings are uniform with height with no such decrease in the number of occupants served by the stairs. 
In tapered buildings the number or width of the egress stairs can be increased for the lower floors to accommodate the increased occupant load. However, for tall buildings of uniform cross section the cumulative occupant load can lead to congestion, and the number of stairs needed to accommodate simultaneous egress would require so much space that the building would not be economical. Here, emergency plans rely on phased evacuation; but this should theoretically include fire endurance for any building elements that might impact egress at least as long as the required egress times.

Up to and including the Empire State Building these tall buildings were typically Type $1 \mathrm{~A}(4 \mathrm{hr})$ construction. Thus a reasonable limit on egress times would be $2 \mathrm{~h}$ (the $4 \mathrm{~h}$ fire resistance time with a safety factor of 2). From a flow and egress time perspective, using a conservative 1 min per floor descent rate would limit heights of Type 1A buildings to 100 floors. A rate of 50 floors per hour is used to allow for notification, pre-movement, and horizontal travel times as well as some rest stops in the stairs.

Beginning with the World Trade Center Towers it became common to permit Type 1B construction (3 hr). With an occupant load of 390 per floor (110 floors) and three egress stairs (6 $1 / 2$ units of total exit width) total (simultaneous) evacuation times were estimated at about four hours (including congestion, queuing, and transfer corridors), which is consistent with the egress times observed in the 1993 bombing. Applying the criterion of a total egress time of half the fire resistance time, one would want the building to withstand a fire for $8 \mathrm{~h}$ or until complete burnout of all combustibles, whichever occurs first.

\section{PEOPLE ARE BIGGER AND LESS FIT}

In the early $20^{\text {th }}$ Century the 22 in $(1.1 \mathrm{~m})$ unit of exit width was sufficient for the $95^{\text {th }}$ percentile US adult male. In the $21^{\text {st }}$ Century this is no longer the case. The American male is larger with a $95^{\text {th }}$ percentile shoulder width of 20 in $(510 \mathrm{~mm})$, which requires a 28 in unit if exit width and a 56 in $(1.4 \mathrm{~m})$ stair (applying Templer's 4 in on each side to account for body sway and personal space). Templer did

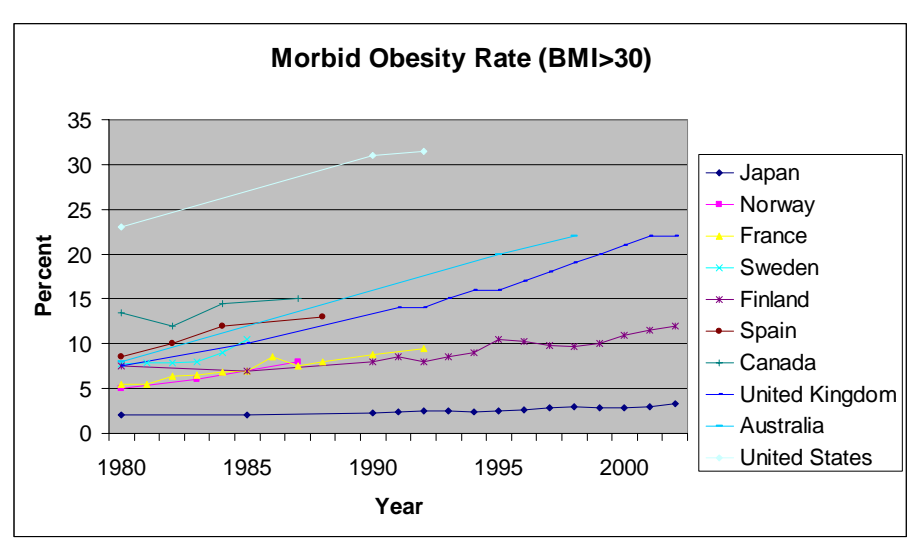

Figure 3 - Obesity rates by country

Data: International Obesity Task Force, EU Briefing paper, 2005 not allow the 4 in to a handrail since people were narrower at the waist and hip than at the shoulder, but this is no longer true.

The physical condition of the average occupant is such that the exertion of descending many flights of stairs is no longer possible without frequent rest stops and a slower pace. 
High percentile $\left(95^{\text {th }}\right)$ average weights have increased substantially in recent years (Fig 3), and the number of people reporting that they need assistance due to physical conditions has also increased.

The WTC Investigation found $6 \%$ of occupants reporting the need for assistance in traveling down stairs. These increases can be attributed to the widespread adoption of modern accessibility regulations that have made it easier for people with mobility limitations to be more active in society, and to the recognition that there are many conditions not generally considered to be disabilities that can limit the ability of people to move down many flights of stairs.

\section{NEW TECHNOLOGIES}

A number of new technologies are available to address limitations of the past. One of the most promising is the ability to design and operate elevators safely and reliably during fires. Here the ability to provide reliable power, sophisticated operational protocols, and real time monitoring of critical functions, permit the use of protected elevators as a primary means of egress in fires. Further, fire departments have recognized the need for protected elevators to provide logistical support to operations in tall buildings.

Modern fire alarm systems combine reliability, flexibility, and advanced functionality that permits real time monitoring and tactical support for incident management not previously possible. With the advent of the industry standard $^{24}$ fire service interface in the U.S., it is possible for the incident command to actively manage the evacuation process for improved safety and efficiency. For example, it is possible to monitor conditions in the stairways in real time and to advise occupants to change stairs to avoid congestion, especially where crossover corridors or refuge floors are provided. Inexpensive cameras and digital image processing software make it possible to present images for action to fire service personnel only when issues arise, permitting a few personnel to monitor many locations.

Advances in photoluminescent materials now permit issues of lighting levels and contrast within stairs to be addressed without the need for complex emergency power systems(Fig 4). When fully charged by continuous ambient light these materials provide more light for longer periods and can be applied to highlight stair nosing and handrails and as path lighting in transfer hallways.

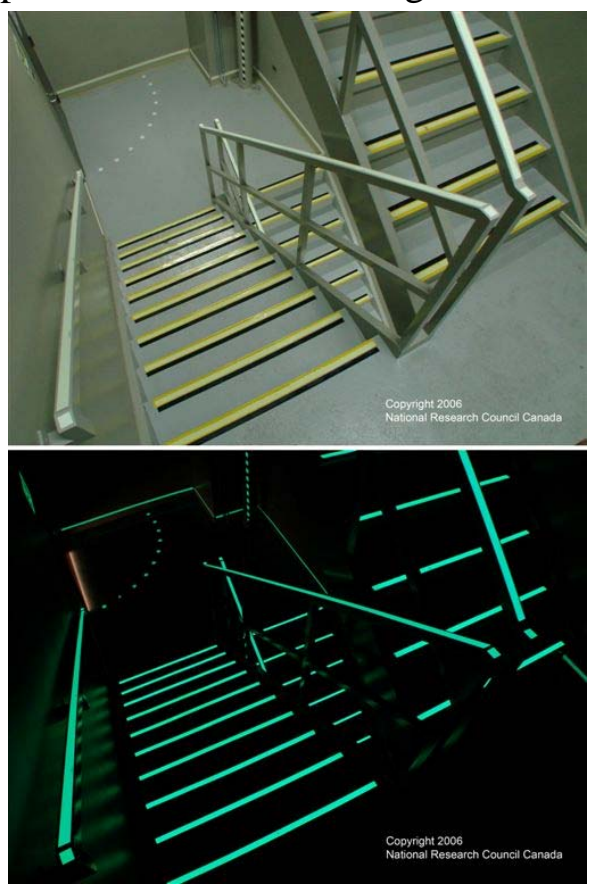

Figure 4 - Photoliminescent materials can be used to illuminate stairways Source: NRC Canada (used with permission) 


\section{REFUGE FLOORS}

The incorporation of refuge floors in tall buildings in Asia also represents a new approach worthy of review. As discussed earlier, these are arranged every 20 to 25 floors (generally on mechanical floors) to provide a protected area for occupants to rest temporarily on their journey down the stairs and to cross over from one stair to another. Refuge floors are also intended as protected space in which people with disabilities can await rescue by the fire department (fire service elevators are generally arranged to be able to stop at the refuge floors).

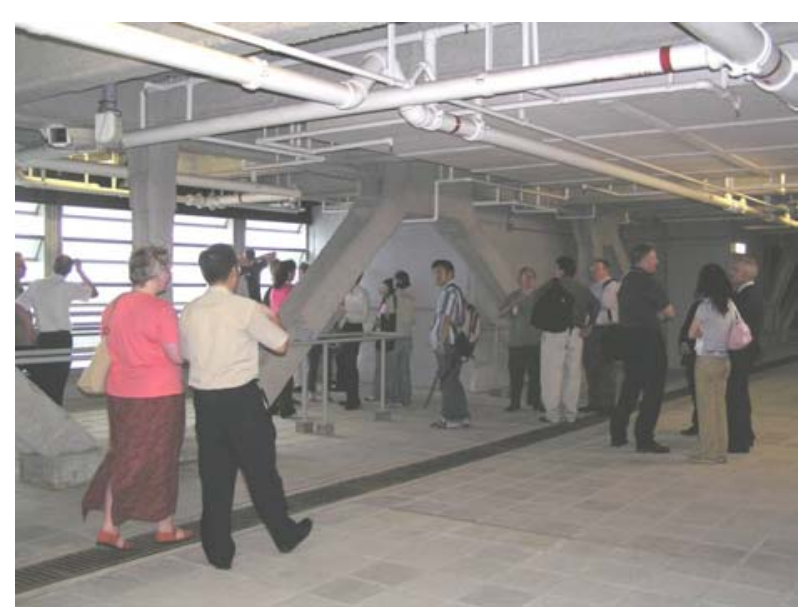

Figure 5 - Refuge floor in a Hong Kong high-rise during a fire drill Source: Arup (used with permission)

Since these requirements are fairly new there have been no emergency evacuations of buildings so equipped, but there have been evacuation drills that have shed some light on performance (Fig 5). One issue identified in drills is that many occupants decide to wait on the refuge floor for the "all clear" which fills the available space, preventing additional people to enter the floor from the stair. Without wardens or fire service personnel stationed on the floor to keep people moving, the purpose is defeated. It is not clear in a real emergency if this will be a problem since occupants may be motivated to get completely out of the building.

\section{PERFORMANCE METRICS FOR EGRESS SYSTEMS}

In the U.S., Australia and Japan, the design of egress systems are based on the population of the largest, single floor. In U.K., Spain, and China the number of floors served by the stair impacts the total number of people served by a stair of a given width. Yet in any performance analysis of an egress system in these or other countries, regulators require a timed egress analysis to estimate Required Safe Egress Time (RSET) which is compared against Available Safe Egress Time (ASET). ASET is generally determined by fire modeling to estimate conditions in the egress path that might lead to injury or death.

Clearly the appropriate performance metric is time, yet there is no regulatory performance objective nor design criterion for egress systems in terms of time in any of the codes examined. As early as 1914 the Safety to Life Committee recognized that designing egress stairs on the basis of flow (of occupants down the stair) required some "assumed time in which it is safe to exit the building" which is the ASET mentioned above.

For compliance with the life safety objective of any building regulation, it is reasonable to determine ASET as the time to reach potentially incapacitating or lethal conditions 
anywhere within the means of egress. Considering the fact that the means of egress is designed to protect people within it from exposure to fire or smoke, it is also reasonable to assume that a limiting ASET would be the time to fire-induced partial structural collapse. If burnout occurs before collapse, there is no theoretical limit to the ASET though a reasonable value may be prescribed instead. Currently, the fire resistance time of structural components and assemblies rated by a standard fire exposure in units of time has not been shown to correlate with the time to structural failure of the component, assembly, or system as a whole for an arbitrary real fire. Clearly, some factor of safety that is appropriate for the level of uncertainty is needed in order to approximate ASET by the fire resistance rating in cases where local collapse is estimated to occur before burnout.

Based on these arguments an appropriate performance objective for egress systems design may be that the time needed for total evacuation of the building be less than the required fire resistance time for the primary structural frame (i.e., the columns and other structural members including girders, beams, trusses, and spandrels having direct connections to the columns and bracing members designed to carry gravity loads). Where the fire resistance time is determined by test against a standard fire curve (i.e., ASTM E119 or ISO 834) a safety factor could be applied that is large enough to account for the variability of egress performance and the uncertainty in the fire resistance time representing the time to failure of at least one element of the primary structural frame. Where the fire resistance time is determined by engineering analysis following the Natural Fires or other similar method which accounts for the actual design level fire event, some lower safety factor could be applied since the predicted time to structural failure would be expected to be less uncertain although the egress variability would be the same. For the sake of this discussion factors of safety of 2.0 and 1.5 , respectively will be used; however, the actual values represent policy decisions that need to be established through the model code development and regulatory adoption processes.

Since high-rise buildings in any of the codes examined for this paper are required to have a primary structural frame of not less than 3-h fire resistance as determined by

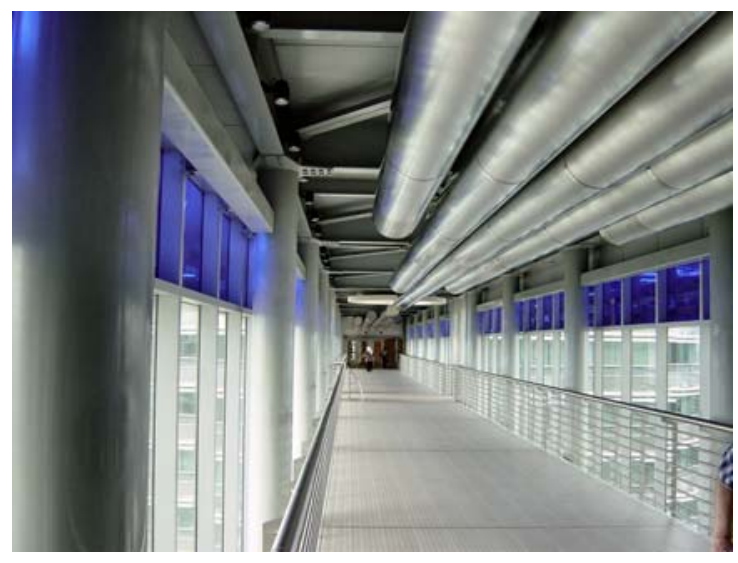

Figure 6 - Interior of skybridge connecting the Petronas Towers at mid-height Source: Bukowski (used with permission) standard test, the total evacuation time would be required to be no more than $1 \frac{1 / 2}{h}$, reflecting the safety factor of 2.0 discussed above. Recent analyses have shown that evacuation times of $1 \mathrm{~h}$ may be achievable with stairs in buildings up to about 50 stories and with a combination of protected elevators and stairs for most buildings of any height, without increasing the number or size of the stairs or elevators above current practice; this objective is clearly practicable ${ }^{25}$. 
These same arguments can be applied to the issue of a performance objective for fire department access. Since U.S. codes require provision of $30 \mathrm{~min}$ of local water supply in high rise buildings, it is reasonable to say that it should be possible for the fire department to be able to put water on a fire at any height within $30 \mathrm{~min}$. The $30 \mathrm{~min}$ local water supply requirement includes both sprinkler and standpipe flows, and in that initial $30 \mathrm{~min}$ there would be no standpipe flow, so this results in a safety factor. Using protected elevators fire departments can meet the 30 min objective for buildings of any height. Using fire department response time and a conservative estimate of 2 min per floor for ascent with equipment it is straightforward to determine the height threshold for fire service access elevators.

\section{RETHINKING EGRESS SYSTEMS DESIGN}

Some will argue that, other than some specific extreme events like the World Trade Center attacks, there have been no reported failures to evacuate even the tallest buildings. Therefore there is no reason to change what has been done for more than 100 years. There are several things wrong with this argument.

First, there have been some failures in tall building evacuations. A real evacuation of both Petronas Towers for a bomb scare in 2001 resulted in an evacuation time of several hours when the skybridge (Fig 6) jammed with occupants crossing to the opposite tower in accordance with the original evacuation plan. By incorporating elevator egress for floors above the skybridge the total time for total (simultaneous) evacuation of both towers was observed in a drill to be $20 \mathrm{~min}^{26}$. For Taipei 101 an evacuation drill conducted prior to opening showed a total evacuation time of about $2 \frac{1 / 2}{h}$. The fire brigade reported being uncomfortable with this time. Incorporating protected elevators for egress from the upper floors reduced that time to just under one hour ${ }^{27}$.

As discussed previously, buildings have become much taller and heights continue to increase beyond the ability of anyone from the upper stories to egress down stairs. Also, these buildings are much less tapered with height compared to early skyscrapers, with larger occupant loads in the upper floors. People today are larger and less fit, and accessibility regulations have resulted in a growing fraction of occupants with mobility limitations requiring egress assistance. Increasingly, there are people in buildings who cannot be moved down

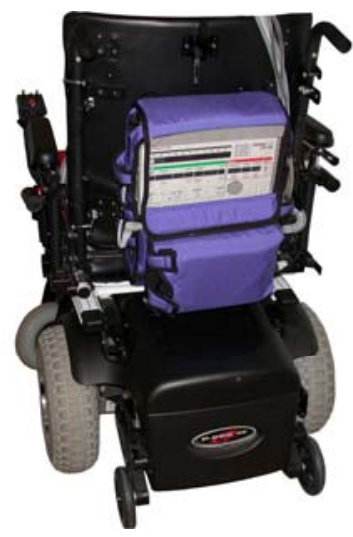

Figure 7 -Typical powered wheelchair with attached ventilator is used by people with severe disabilities such as Christopher Reeve. He could only survive away from his chair for a few minutes, and he and the chair weighed $300 \mathrm{~kg}(660 \mathrm{lb})$ (photo used with permission) stairs under any circumstances (Fig 7). Following the collapse of the WTC buildings, occupants of tall buildings are reluctant to delay egress and are not comfortable with long egress times. 


\section{STRAWMAN EGRESS SYSTEM PERFORMANCE METRICS}

Based on the prior review and discussion the following suggestions are provided to facilitate the needed rethinking of the philosophy and details of egress system design for buildings. Thresholds and performance levels are public policy decisions that need to be made in conformance with the methods in place for making regulatory decisions in an individual country. These usually require public consultation and a legislative or administrative process. The suggestions provided in the following sections include provisions that would be formatted as code requirements (in bold) followed by explanatory material.

\section{Performance Objectives}

Buildings shall be designed and arranged such that the responding fire brigade can access a fire on any floor and begin suppression operations within $\mathbf{3 0}$ minutes of the transmission of the original alarm, $95 \%$ of the time.

It is expected that this objective will require the provision of a fire service access elevator in buildings with occupied floors more than $30 \mathrm{~m}(100 \mathrm{ft})$ above the level of fire department access. The $95 \%$ criterion is intended to recognize that conditions may exist that prevent the objective from being met on occasion, but that most expected conditions should be considered. The $30 \mathrm{~min}$ limit is based on the U.S. requirement for local water supply for automatic suppression systems.

Buildings shall be designed and arranged such that $98 \%$ of the expected occupants are able to evacuate the building without outside assistance in a time not exceeding half of the required fire resistance time of the primary structural frame.

In the U.S. model building codes buildings taller than 4 stories are required to be Type I construction with either 3-h (Type IA) or 2-h (Type IB) fire resistance as determined in ASTM E119 for elements comprising the primary structural frame. Thus the maximum total egress time (applying a safety factor of 2.0 ) would be either $1.5 \mathrm{~h}$ or $1 \mathrm{~h}$, respectively. The $98 \%$ reflects an expectation that there may be some occupants who will require the assistance of the fire brigade for egress, but that even most occupants with disabilities can either self-evacuate or require only assistance from other occupants. It is expected that this requirement would result in occupant egress elevators in Type IA buildings taller than 80 stories and Type IB buildings taller than 50 stories.

\section{Protected Fire Service Access Elevators}

Where required, at least one elevator serving every floor shall be designated for use by the fire service in emergencies. This elevator shall be powered by normal and emergency power, with both power and control wiring protected by fire resistant construction at least equal to the fire resistance requirement applicable to the primary structural frame. Any alarm transmission to the fire brigade shall result in the designated fire service elevator being taken out of normal service and recalled to 
the designated level. The designated fire service elevator shall open on every floor into a protected lobby with direct access to a building stair containing a standpipe and any other required equipment for fire department use. The elevator equipment shall be protected from compromise by water from sprinklers or firefighting. Reliable communication with fire service personnel using the elevator and monitoring of critical functions in the fire command center shall be provided.

Fire service access is not normally considered part of the egress system design except to the extent operations within the building can have an impact on the evacuating occupants. The only code found where this is explicitly discussed is in UK Approved Document B which suggests that in tall buildings one stair may need to be discounted because it will be blocked by operations on the fire floor and one or two floors below. It should also be recognized that this "attack stair" may be compromised on any floor(s) above the fire due to smoke leakage into the stair from the fire floor when the hose is advanced onto the floor, since the standpipe is located within the stair. Only where a vestibule is provided (in the U.S. called a smokeproof tower or fire tower) would the stair itself be kept mostly smoke free. However, the evacuation assistance provided by the fire service, especially by the fire service elevator, will have a significant impact on the success of the evacuation.

\section{Protected Occupant Egress Elevators}

Where required, all elevators except any designated fire service elevator(s) shall be designed and arranged to permit their safe use for occupant evacuation. These occupant elevators shall be powered by normal and emergency power, with both power and control wiring protected by fire resistant construction at least equal to the fire resistance requirement applicable to the primary structural frame. Occupant egress elevators shall operate in a hoistway protected from the adverse effects of water and opening into a protected lobby on each floor that serves as an area of refuge while awaiting the elevator. The lobby shall be sized to accommodate $75 \%$ of the occupant load of the floor at $0.5 \mathrm{~m}^{2}\left(5 \mathrm{ft}^{2}\right)$ per person. Elevator lobbies shall have direct access to an egress stair and be provided with two-way communications to the fire command center and approved means to provide real time information to waiting occupants.

On a fire alarm the elevators shall begin evacuating occupants of the fire floor and two floors above and below the fire floor, taking them to the level of exit discharge before returning for another load until all 5 floors are evacuated. On a decision for a full building evacuation by the official in charge the elevators shall evacuate all remaining occupants from the highest floors and proceeding downwards, shuttling occupants to the level of exit discharge before returning for another load. Information systems on all floors except the level of exit discharge shall communicate to occupants the status of the system and the estimated wait time. Information systems on the level of exit discharge shall indicate that the elevators are out of service and people should not enter. 
Occupant egress elevators are by far the fastest means of evacuating a tall building. In normal service the number, size, and speed of passenger elevators in most buildings are designed to be able to move approximately $10 \%$ of the total population of the building from random floors to the level of exit discharge in $5 \mathrm{~min}$. This means that any building of any height can be totally evacuated by elevator in one hour or less without increasing the number, size, or speed of the elevators normally provided. Modern elevators utilize computerized controllers capable of sophisticated operational protocols, and the addition of real time monitoring and information systems can add the necessary reliability and guidance to users to permit their use for egress during fires. In addition, occupants use the building elevators every day for normal ingress and egress. The use of the elevators for egress in fires is not appreciably different as long as the people are provided with sufficient information to make decisions.

Considerable effort by NIST, the elevator industry, the American Society of Mechanical Engineers (ASME), and the building code organizations is being put into the development of standards and code requirements for protected elevators both for fire service access and for occupant egress. The language suggested above for both purposes is consistent with that effort but the activity needs to play out to arrive at a consensus on requirements for the elevator equipment. Similarly, proposals are being considered by the model building code organizations for the building code related parts of the systems. Again, the performance objectives above are consistent with those proposals but the process should play out to arrive at a consensus of the involved parties.

\section{Stair Width}

Where stairs are the primary means of vertical egress in fires and other emergencies such stairs shall be a minimum width of $1400 \mathrm{~mm}(56$ in). Where protected elevators are provided as the primary means of vertical egress in fires and other emergencies stairs shall be a minimum width of $1100 \mathrm{~mm}$ (44 in).

Wider stairs are needed to accommodate the increased body size of occupants but this additional width is not needed where most occupants would be expected to egress by elevator. Further, any building provided with occupant egress elevators would also have fire service access elevators, eliminating the issue of counterflow except for the fire floor and one or two floors below in the attack stair.

\section{Stair Capacity}

Where stairs are the primary means of vertical egress in fires and other emergencies sufficient stair capacity shall be provided to accommodate the maximum number of building occupants on all floors except any with direct access to the outside, within the stairways. Where protected elevators are provided as the primary means of vertical egress in fires and other emergencies sufficient stair capacity shall be provided to accommodate at least half the maximum number of building occupants on all floors except any with direct access to the outside, within the stairways. Any floor containing an assembly space that results in a higher occupant load when 
provided with an area of refuge sized to accommodate $100 \%$ of the occupant load of that floor with direct access to a stair and an occupant egress elevator, shall be permitted to neglect the additional occupant load for the purpose of determining stair capacity.

While the philosophy of "storing" stationary occupants in stairs is not intended, the stairs remain a more protected space within the building. Some occupants may choose to use stairs (particularly on the lower floors) and the ability to find refuge in stairs is an important redundancy. Where occupant egress elevators are provided it is expected that most occupants will use them, but some minimum capacity for refuge is needed. Likewise, the provision of assembly occupancies (restaurants, bars, conference facilities, observation decks, ...) that result in local concentrations of additional people traditionally required additional stair capacity that continued through the building to the level of exit discharge. With occupant egress elevators most of these people will egress by elevator and it is only necessary to accommodate them temporarily while they await the elevators.

The capacity of an egress stair is defined as the number of occupants who can descend the stair in a time equal to one half the fire resistance time of the primary structural frame, at a flow rate of 47 occupants per minute per meter of stair width (26 occupants per minute per unit of exit width). (The design flow rate is a policy decision among $(81,47$, or 30$)$ occupants per minute per meter with 47 being used in this example).

The number of occupants that could be served by a stair should be based on the flow or discharge rate (Flow Method as defined in the 1935 NBS report) over 1h (Type IB) or 1 $1 / 2 \mathrm{~h}$ (Type IA). Table 1 below shows discharge rates per hour, per (22 in) unit and per meter, and for a 1100 (44 in) and 1400 (56 in) stair, based on assumed flows of 45 occ/min/unit (which has no specific scientific basis but is used in the UK Approved Document B), 26 occ/min/unit (based on the work of Togawa and Pauls), and 16 occ/min/unit (based on estimates from the NIST WTC report). If one used a flow rate of 26 occ/min/unit, a single $1100 \mathrm{~mm}$ (44 in) stair could serve 2160 people (4320 for two stairs) and a $1400 \mathrm{~mm}$ (56 in) stair could serve 2750 people (5500 for two stairs). This would be the total number of occupants served by the stair(s) on all floors except those with direct egress to the outside (who would not use the stairs). This would also be limited to 50 or 80 stories since it would take longer than (1 or 1 1/2) hours to descend from greater heights.

Table 1 - Total Number of Occupants Served by an Egress Stair Based on Flow

\begin{tabular}{|l|l|l|l|l|l|}
\hline $\begin{array}{l}\text { Flow } \\
\text { occ/min/unit }\end{array}$ & $\begin{array}{l}\text { Flow } \\
\text { occ/min/meter }\end{array}$ & $\begin{array}{l}\text { Dis Rate } \\
\text { occ/h/unit* }\end{array}$ & $\begin{array}{l}\text { Dis Rate } \\
\text { Occ/h/meter* }\end{array}$ & $\begin{array}{l}\text { Dis Rate } \\
\text { Occ/h/1.1 m* }\end{array}$ & $\begin{array}{l}\text { Dis Rate } \\
\text { Occ/h/1.4 m* }\end{array}$ \\
\hline 45 & 81 & 2700 & 4860 & 5350 & 5830 \\
\hline 26 & 47 & 1560 & 2820 & 3100 & 3380 \\
\hline 16 & 30 & 960 & 1800 & 1980 & 2160 \\
\hline
\end{tabular}

* Multiply by 1.5 for Type IA Construction where ASET is $1 \frac{1}{2} \mathrm{~h}$ 
In a system designed by the flow method it is important to ensure that the flow through doors is equal to or greater than the stair flow so that flow restrictions and congestion is avoided. This raises an interesting issue. There seems to be consensus that flow through doors is about 60 occupants per minute per door regardless of width. If a design stair flow rate of 26 occupants per minute per unit is selected, the stair flow in a 2-unit (44 in, $1100 \mathrm{~mm}$ ) stair is 52 per minute which can be accommodated by a single door. In a $2 \frac{1}{2}$ unit (56 in, $1400 \mathrm{~mm}$ ) stair the flow is 65 per minute which will theoretically result in an accumulation of 5 people per minute at the upstream side of a single door. It needs to be determined if 56 in stairs need double doors to prevent congestion, as this can be a significant cost issue in design.

\section{Stair Geometry}

Current requirements in the building codes reviewed are consistent with the research recommendations.

\section{Refuge Floors}

Horizontal transfer corridors designed as means of egress components shall be provided every 25 floors (generally on mechanical floors) to link all egress stairs and to provide the ability to safely move between stairs.

The initial experience with refuge floors indicates that the provision of a means to transfer stairways has merit but the provision of a large space to "rest" encourages delays in evacuation that may be counterproductive to safety. The protected lobby with direct access to a stair provided as part of the occupant egress elevator system can provide for rest stops if needed, but most occupants would use the elevators and not need to rest. Thus, it is recommended to not provide refuge floors but to consider a protected horizontal transfer corridor linking all stairways on the mechanical floors. The 25 floor increment is based on the Asian requirement for refuge floors but could be flexible where only stairway crossovers are provided.

\section{Evacuation Management}

Video cameras shall be installed every 5 floors in every egress stairway and in every egress elevator lobby with the images displayed in the fire command center. Image analysis software shall be employed to minimize the fire department burden for monitoring these images.

The potential for changing conditions impacting the safety and efficiency of the evacuation suggests that full building evacuations need to be actively managed. The addition of cameras in the stairs and egress elevator lobbies which can be monitored in the fire command can facilitate such management. Using available software developed for the security industry the monitoring burden in fire command can be minimized. Images from cameras in stairs would be kept in background except when no movement is detected for some time interval, indicating no people or no movement of people. Images 
from lobby cameras would be kept in background except when movement is detected, indicating there are people in the lobby needing pickup. If that floor has not yet been evacuated this information can be registered with the elevator controller. If the floor has already been evacuated the presence of stragglers would be noted to the fire department. Placement every 5 floors is considered reasonable for the purpose. More frequent is probably not necessary for active management of egress but less frequent might permit unobserved blockages.

\section{CONCLUDING REMARKS}

The increasing height of buildings coupled with changing demographics and public concerns about the safety of tall buildings have led to a call for a fundamental rethinking of egress systems. This paper provides a review of the approaches currently found in building regulations internationally, and attempts to identify the origins of these specifications including the extent to which they may be based on scientific data or consensus opinion. The case for moving to a performance metric of time is presented and a set of criteria for evaluating egress systems against safe egress time is suggested. Performance criteria based on practical objectives are suggested but these and suggested regulatory thresholds need to be vetted through the existing consensus process of model code development and regulatory adoption followed in the adopting jurisdiction. The result should be a design approach that addresses the needs of occupants and buildings of all heights with criteria based on sound engineering principles.

\section{REFERENCES}

\footnotetext{
${ }^{1}$ Proc of the $18^{\text {th }}$ Annual Meeting, National Fire Protection Association, Boston, MA 1914.

2 Bukowski, R.W., Progress Toward a Performance-Based Codes System for the United States, Applications of Fire Safety Engineering. Symposium for '97 FORUM. Proceedings. FORUM for International Cooperation on Fire Research, Tianjin Fire Research Inst. and Shanghai Yatai Fire Engineering Co., Ltd. October 6-7, 1997, Tianjin, China, 97-107 pp, 1997.

${ }^{3}$ Proc of the $17^{\text {th }}$ Annual Meeting, National Fire Protection Association, Boston, MA 1913.

${ }^{4}$ Design and Construction of Building Exits, National Bureau of Standards Miscellaneous Publication M151, Washington DC, 1935.

${ }^{5}$ Building Exits Code, NFPA 101-T, National Fire Protection Association, Boston, MA, 1927.

6 Togawa, K., Study on Fire Escapes Basing on the Observations of Multitude Current, in Building Research Institute of Japan, U.S./Japan Government Cooperative Program on Natural Resources (UJNR) Panel on Fire Research and Safety, Vol 2, Human Behavior, Tokyo, Japan, pp1-3, 1976.

${ }^{7}$ Pauls, J. L., Building Evacuation and Other Fire Safety Measures: Some Research Results and their Application to Building Design, Operation, and Regulation, in D.H. Carson, ed., Man-Environment Interactions: Evaluations and Applications - The State of the Art in Environmental Design Research (EDRA 5) Part 4, pp 147-168, 1974.

${ }^{8}$ Fruin, J.J., Pedestrian Planning and Design, Elevator World, Mobile, AL, 211 pp, 1987.

${ }^{9}$ Predtechenskii, V.M. and Milinskii, A.I., Planning for Foot Traffic Flow in Buildings, Translated and Published by NBS, 240 pp, 1978.

${ }^{10}$ Averill, J.D. et al, Federal Building and Fire Safety Investigation of the World Trade Center Disaster, Occupant Behavior, Egress, and Emergency Communications, NCSTAR 1-7, NIST, Gaithersburg, MD 2005.

${ }^{11}$ Life Safety Code (2006 ed), Figure A.7.3.4.1.1 (b), NFPA, Quincy MA 2006.

12 Templer, J., Stair Shape and Human Movement, Ph.D. dissertation, Colombia University, 1974.

13 Templer, J., Mullet, G.M., Archea, J., and Margulis, S.T., An Analysis of the Behavior of Stair Users, NBSIR 78-1554, NBS, 1978.
} 
${ }^{14}$ Blondel, F., 1675-1683. Cours d'Architecture Enseigne dans l'Academie Royale d'Architecture, Paris.

${ }^{15}$ Templer, J., The Staircase, Studies of Hazards, Falls, and Safer Design, MIT Press, 1992.

${ }^{16}$ Fitch, J.M, Templer, J., and Corcoran, P., The Dimensions of Stairs, Scientific American, 231(4), 1974.

${ }^{17}$ Bukowski, R.W. and Kuligowski, E.D., The Basis for Egress Provisions in U.S. Building Codes, InterFlam 2004, Edinburgh, UK, July 2004.

${ }^{18}$ Building Code of Australia, 2006 ed., Australian Building Codes Board, Canberra, AU, 2006.

${ }^{19}$ Approved Document B: Fire Safety, 2006 ed., Department of Communities and Local Government, London, 2006.

${ }^{20}$ Codigo Tecnico (Building Code), Basic Document SI: Fire Safety, Ministry of Housing, Madrid, 2003.

${ }^{21}$ Code of Practice for the Provision of Means of Escape in Case of Fire, Building Authority of Hong Kong, 1996.

${ }^{22}$ Code for Design of Building Fire Protection, National Standard GBJ 16-87, People’s Republic of China, Beijing 1995.

${ }^{23}$ Building Standard Law of Japan, Building Center of Japan, 2004.

${ }^{24}$ Fire Service Annunciator and Interface, NEMA SB30, Natiopnal Electrical Manufacturers Association, Rosylin, VA 2006.

${ }^{25}$ Bukowski, R.W., Emergency Egress Strategies for Buildings, Proc InterFlam 2007, Interscience Communications, London 2007.

${ }^{26}$ Arliff, A., Review of Evacuation Procedures for the Petronas Twin Towers, Strategies for Performance in the Aftermath of the World Trade Center. CIB-CTBUH Conference on Tall Buildings. Proceedings. Task Group on Tall Buildings: CIB TG50. CIB Publication No. 290. October 20-23, 2003, Kuala Lumpur, Malaysia, Shafii, F.; Bukowski, R.; Klemencic, R., Editors, 35-42 pp, 2003.

${ }^{27}$ Hsiung, K.H., Wen, W.J., Chien, S.W., and Shih, B.J., A Research of the Elevator Evacuation Performance for Taipei 101 Financial Center, Proc $6^{\text {th }}$ Int Conf on Performance-based Codes and Fire Safety Design Methods, June 14-16, 2006, Tokyo, Japan, SFPE Bethesda, MD 213-225p, 2006. 